\title{
Science Mapping of the Knowledge Base on Sustainable Leadership, 1990-2018
}

\author{
Philip Hallinger ${ }^{1,2, *(1)}$ and Suparak Suriyankietkaew ${ }^{3}$ (I) \\ 1 Center for Research on Sustainable Leadership, College of Management, Mahidol University, \\ 69 Vipavadee Rangsit Rd., Bangkok 10400, Thailand \\ 2 Department of Educational Leadership and Management, University of Johannesburg, Auckland Rd., \\ Johannesburg 2006, South Africa \\ 3 College of Management, Mahidol University, 69 Vipavadee Rangsit Rd., Bangkok 10400, Thailand; \\ suparak.sur@mahidol.ac.th \\ * Correspondence: hallinger@gmail.com
}

Received: 25 November 2018; Accepted: 14 December 2018; Published: 19 December 2018

\begin{abstract}
The rise of sustainable development as a field of applied research has been observed across a wide range of disciplines. Successful change towards sustainability in organizations and societies requires leadership to provide a vision, set direction, and motivate people to move towards new goals. Thus, sustainable leadership is emerging as a new domain of study within the field of management. This review of research employed science mapping tools to examine 952 Scopus-indexed documents explicitly concerned with sustainable leadership. The goals of the review were to document the size, growth trajectory, and geographic distribution of this literature, identify key journals, authors, and documents, analyze the intellectual structure of this knowledge base, and highlight emerging topics. The review documented a modest-sized knowledge base of recent vintage, concentrated in Western developed societies but global in scope. Six Schools of Thought were identified within this knowledge base, one of which-Sustainable Leadership-was singled out for attention. As the first bibliometric review of research on sustainable leadership, this review provides a reference for scholars entering this domain, as well as guidance with respect to high value frameworks, foci for future research, and practical implications.
\end{abstract}

Keywords: sustainable leadership; sustainability leadership; knowledge production; science mapping; bibliometric review

\section{Introduction}

Over the past sixty years, management scholars have evidenced interest in examining an expanding range of conceptual models that describe leadership in organizations [1]. These include situational leadership, transactional leadership, transformational leadership, distributed leadership, autocratic leadership, participatory leadership, ethical leadership, authentic leadership, responsible leadership, change leadership, and positive leadership. Leadership has been studied, both in relation to forces that shape leader practices, as well as to effects of leadership behavior on staff and organizations [1].

While research on organizational leadership has made impressive progress over these past decades, the literature continues to emphasize and study leadership effectiveness within 'closed systems' [1]. That is, 'effective leadership' is most frequently defined and measured in terms of effects on internal organizational measures, such as staff job satisfaction, commitment, organizational citizenship behavior, task performance, and less frequently, firm performance [1-3]. It has been less 
common for scholars to conceptualize the effects of organizational leadership in terms of leader and organizational impact on the broader society [4-8].

This limitation of leadership research comes to the fore when we examine 'sustainability' in organizations and society $[4,6,8]$. A 'sustainability lens' reframes the enactment of leadership in organizations that are part of an open system, and embedded in an evolving national and global context $[9,10]$. This reinterpretation of the 'outcomes' of leadership are reflected in the increasingly popular metrics designed to measure the 'triple bottom line' of organizational performance-social, environmental, and economic outcomes [6,11-13]. This movement towards a broader conceptualization of the goals and responsibilities of organizations and their leaders means that we can no longer rely as confidently on findings from past research on 'effective leadership' [1,2,14].

This reorientation of the 'ends', towards which leaders strive has been spurred on largely by forces in the environment of organizations [8,15-17]. Climate change, scarcity of resources, economic integration, cultural conflicts, disruptions caused by human migration, technological innovations, and political instability have created a world in which organizational leaders must pay closer attention than ever to their local and global environments $[18,19]$. These developments led the United Nations to define a set of 'sustainable development goals' (SDGs), with applicability to organizations across all sectors and throughout the world [20]. Indeed, the SDGs were designed to reorient global socio-economic development and have, subsequently, raised the stakes for organizational leaders to develop a broader vision of the sustainability of both their organizations and the societies in which they are located [5,6,21-23].

These changes in the environment of organizations have led to the emergence of new models of leadership, referred to, alternatively, as 'sustainable leadership' [4,5,8,24-27], or 'sustainability leadership' [28-32]. Although scholars have, over the past 15 years, carried out numerous studies of sustainable leadership, there have been few efforts to review accumulated theory and research on this emerging approach to leading organizations [23]. For the sake of parsimony and clarity, in this paper the authors will refer to sustainable leadership, sustainability leadership, and leadership for sustainable development under the rubric of 'sustainable leadership'.

This bibliometric review of research sought to document and synthesize scholarship published on sustainable leadership over the past 30 years. More specifically, the review addressed the following research questions.

RQ1: What is the volume, growth trajectory, and geographic distribution of scholarship on sustainable leadership (SL)?

RQ2: What journals, authors, and documents on sustainable leadership have evidenced the greatest citation impact over the past three decades?

RQ3: What is the intellectual structure of the sustainable leadership knowledge base?

RQ4: What topical foci in the sustainable leadership literature have attracted the greatest attention from scholars?

Two features distinguish this review from prior efforts to review the knowledge base in sustainable leadership $[19,23,29]$. First, this review sought to develop a comprehensive view of the SL literature, from its birth in the early 1990s to the present, in 2018. Second, this review uses 'science mapping' [33,34] to provide a systematic, bibliometric synthesis of trends identified in nine hundred and fifty-two Scopus-indexed documents. Science mapping is an emerging method of research review designed to synthesize patterns of knowledge production within a discipline, as opposed to synthesizing substantive findings [34-36]. Thus, this review was aimed at documenting the status of the current knowledge base on sustainable leadership, and offering insights that can guide its further development.

\section{Conceptual Background of the Review}

Two conceptual frameworks were employed to guide this review. The first framework establishes sustainable leadership in the organizational and social systems within which it is enacted. The second framework provides a basis for this inquiry into the literature or 'knowledge base' on sustainable 
leadership. The framework proposes a means of conceptualizing a knowledge base in terms of a set of analytical components [34,37-40].

\subsection{Conceptualizing Sustainable Leadership}

Sustainable leadership has been conceptualized with overlapping but sometimes different constructs or themes. Sustainable leadership has its roots in what was earlier termed 'Rhineland management' $[5,8,41]$. Grounded in the 'Rhineland approach to capitalism' employed in Germany, this emphasized different values and practices of managers [41]. Contrasted, for example, with American capitalism, Rhineland capitalism (and management) highlighted the organization's place in and responsibilities to society. Investigations have found that Rhineland leadership, a precursor to sustainable leadership, emphasized a long-term perspective, balanced outcomes, ethical behavior, and corporate social responsibility $[5,8,24,41-44]$.

One of the first conceptual definitions of 'sustainable leadership' was offered by Hargreaves and Fink, in 2004 [4]. They proposed that sustainable leadership was leadership that aims to meet the needs of present-day society, without compromising the ability of future generations to prosper. Ferdig [28] defined a sustainability leader as someone, "who takes responsibility for understanding and acting on sustainability challenges, whether or not they hold formal leadership positions. They lead 'with', rather than 'over' others, in ways that account for the long-term viability of complex, interconnected living systems" (p. 25). Avery and Bergsteiner [25] asserted that, "sustainable leadership requires taking a long-term perspective in making decisions; fostering systemic innovation aimed at increasing customer value; developing a skilled, loyal, and highly engaged workforce; and offering quality products, services, and solutions" (p. 5).

The DNA of sustainable leadership also traces back to scholarship that focused on the role of leadership in bringing about 'sustainable change' $[4,21,22,28,45-48]$, as well as ethical leadership that emphasized corporate social responsibility $[23,49,50]$. The emphasis on values that underlies most conceptions of sustainable leadership further suggests an explicit link to leadership models, such as authentic [51,52], responsible [7,21,53,54], and transformational leadership [2,14,55,56].

A synthesis of these conceptual definitions of sustainable leadership reveals a number of common features that cohere to distinguish this approach to leadership.

- Emphasis on leadership, rather than a unitary leader.

- Long-term vision.

- Broader goals that link organizations to society.

- Ethical behavior.

- Social responsibilities of leaders and organizations.

- Innovation capacity.

- Systemic change.

- Stakeholder engagement.

- Capacity building of stakeholders.

Figure 1 presents a conceptual model that places sustainable leadership within an 'open organizational and social system' $[5,24,25,41]$. In this model, sustainable leadership is enacted in a particular social, cultural, and institutional context, and is grounded in a set of personal and organizational values $[4,8,18,28,52]$. Examples of values that have been proposed to foster sustainability include moderation, prudence, mutual respect, the value of individuals, excellence, innovation, quality, and ethical behavior $[23,24,28,43,44,57,58]$. These values underlie both the vision that leaders and stakeholders strive to achieve, as well as the nature of the leader-follower interactions $[3,23,28,57-60]$. 


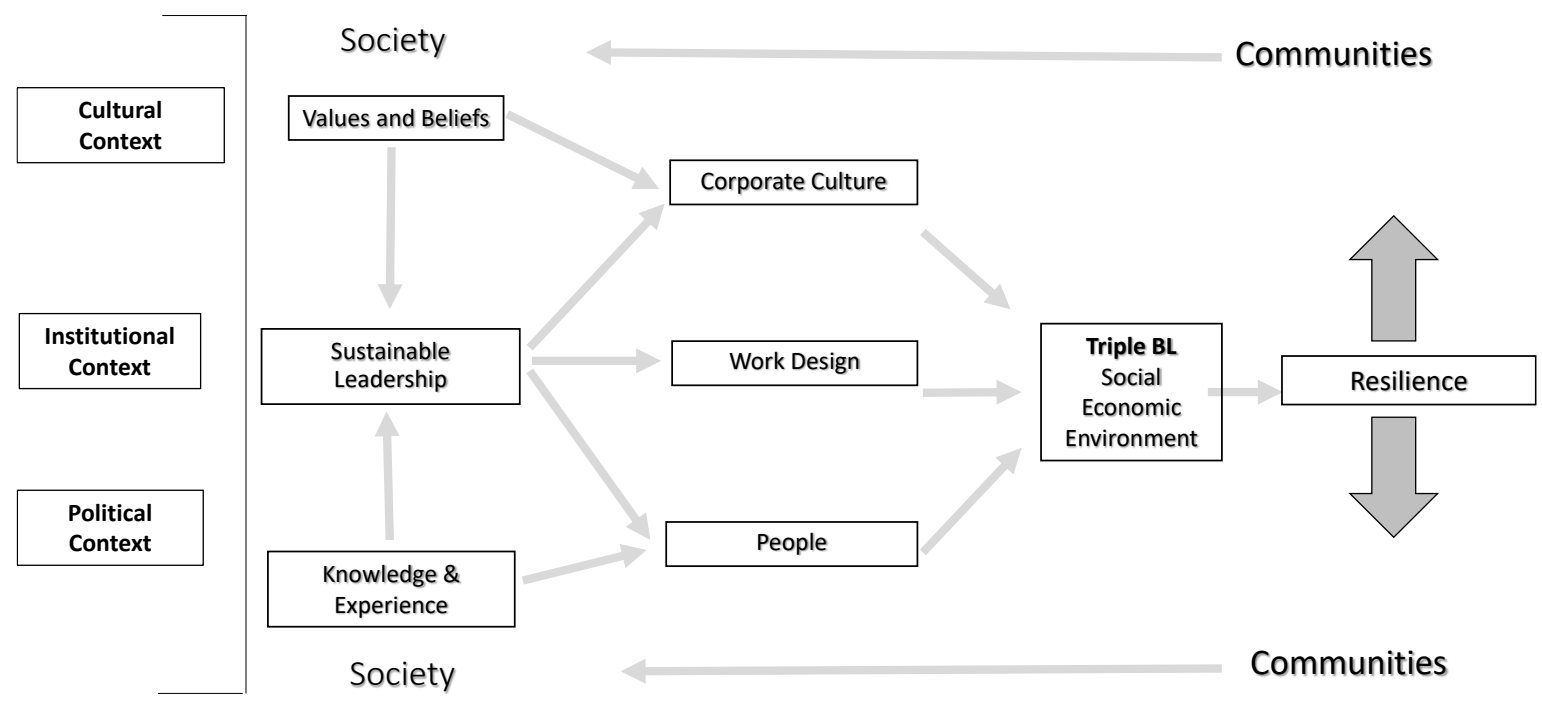

Figure 1. Conceptual model of sustainable leadership.

Sustainable leadership is enacted through collective or distributed efforts aimed at shaping the organizational culture, leading people for both performance and job satisfaction, and redesigning working systems to achieve new goals $[4,24,25,27-29,47,58]$. Sustainable leadership seeks to engage a broad set of stakeholders, both inside and outside of the organization (e.g., staff community, customer, suppliers, government) $[7,31,41,52,57]$. Moreover, as suggested above, sustainable leadership expands upon the earlier definitions of 'effective leadership. Sustainable leadership reorients the mission of organizations towards multiple indicators of success that go beyond the traditional measures of staff satisfaction, commitment, and task performance $[4,11,13,60]$. These typically include, the 'triple bottom-line' of economic, social, and environmental outcomes $[6,12,24,25,60]$.

Finally, the sustainable leadership model draws attention to the fact that even indicators incorporated into the triple bottom-line are not ends in and of themselves. Rather they contribute to the creation of organizations, communities, and societies with the resilience to withstand shocks and unforeseen events $[25,26,53,61-64]$. This feature of the conceptual model further highlights the long-term perspective adopted in the sustainable leadership literature $[24,25,28,41,43,61,64,65]$. This conceptual model informed the current study and its interpretation of the results.

\subsection{Analytical Structure of the Knowledge Base}

This review was geared towards the documentation and synthesis of the sustainable leadership literature from the perspective of a 'knowledge base' [37,38]. We propose that a knowledge base can can be analyzed on the four dimensions of size, time, space, and composition. 'Size' concerns the volume of accumulated knowledge. It is true that the number of published papers, in a domain of knowledge, neither offers specific insights into the quality, nor the accumulation of knowledge. However, productive knowledge accumulation requires a critical mass of research, before findings can cohere into usable knowledge. Thus, for example, it usually takes a period of decades before a field, or even a particular line of inquiry accumulates a sufficient body of knowledge to allow for meta-analytic review [65]. Thus, we assert that 'size' is a necessary, but insufficient precondition for a useful knowledge base.

By definition, knowledge accumulation is not static. Indeed, we view any knowledge base as a dynamic entity, comprised of theoretical and research findings that change over time [66]. Thus, 'time' refers to the publication trajectories within a discipline or a line of inquiry, such as sustainable leadership.

'Space' refers to the 'geographic distribution' of documents within a knowledge base. Spatial distribution not only offers insight into scholarly capacity, but also reveals concentrations as well as 
gaps in knowledge production and accumulation across different societies. This facet of the knowledge base is of particular importance in the fields of study, such as leadership, where the application of knowledge is subject to the influence of contextual factors $[2,22,67,68]$.

The fourth dimension concerns 'composition'. We use this term to refer to the 'intellectual structure' of the knowledge base. Zupic and Čater [34] defined intellectual structure as, "the examined scientific domain's research traditions, their disciplinary composition, influential research topics, and the pattern of their interrelationships" (p. 435). In this review, composition was analyzed in terms of patterns of authorship, journal publication, document impact, and topics in the SL knowledge base.

\section{Method and Materials}

In recent decades, bibliometric review methods have leveraged advances in text and data mining and citation analysis to provide more comprehensive analyses of knowledge accumulation than was possible in the past $[33,34,36]$. This is most evident in the growing use of data syntheses grounded in social network analyses that are capable of illuminating the structural and relational features of disciplines $[35,37,69]$. These advanced methods of bibliometric analysis have already been applied to selected domains in the management literature, including strategic management [35], supply chain management [70], and operations management [39]. The current review employed science mapping, a variant of bibliometric analysis, to analyze the SL knowledge base, on the four dimensions described above.

\subsection{Search Criteria and Identification of Sources}

As a subset of systematic reviews of research, science mapping reviews are explicit about the procedures of constructing the review database. This requires, for example, identification of the 'boundaries' that define the scope of the review as well as elaboration of the procedures used for identifying sources. This review employed the Scopus index which is widely used to generate databases for systematic reviews of research [34,71]. While the Web of Science (WoS) has had higher visibility than Scopus, scholars have recently demonstrated that Scopus's superior coverage makes it a better choice for research reviews in management fields [71,72].

In this review, our sources included journal articles, conference papers, books, and book chapters. Although the timeframe for our document search was open-ended, the first relevant source was published in 1990 [41]. Thus, the effective time frame for this review encompassed the period from 1990 through October 2018. The topical scope for the review included studies of sustainable leadership in any type of organizational setting (e.g., corporate, governmental, non-governmental, community, and education). Although the literature contains numerous papers concerned with aspects of sustainability and leadership, we limited this review to documents that were explicitly framed as focusing on leadership from a sustainability perspective. Thus, we excluded studies that examined elements associated with sustainable leadership (e.g., change, ethics, corporate social responsibility, authentic leadership, and transformational leadership), but which did not explicitly adopt a sustainability perspective towards their enactment.

The authors followed the PRISMA (Preferred Reporting Items for Systematic Reviews and Meta-Analyses) guidelines for conducting the systematic reviews of research [73]. Our initial search used the keywords (TITLE-ABS-KEY ("sustainable leadership") OR TITLE-ABS-KEY ("sustainability leadership")). This yielded two hundred and nine documents. A supplemental search, using the search terms (TITLE-ABS-KEY ("sustainable development") AND TITLE-ABS-KEY (leadership)), yielded two thousand and sixty-nine documents.

These results were reviewed for relevance using the above stated inclusion/exclusion criteria. Initial screening of documents eliminated ineligible source types (e.g., editorials, book reviews, research notes, and letters) and duplicate items. Next titles and abstracts were reviewed to determine their topical relevance. There were two frequent reasons for excluding documents. First, although many documents mentioned leadership in relation to sustainability, it was not the primary focus of the study. 
Similarly, there were numerous studies in which leadership was mentioned in relation to sustainable development, but only in general terms. Application of these exclusion criteria accounted for about $85 \%$ of the documents that were eliminated from the initial database (see Figure 2). This screening process left a final database of nine hundred and fifty-two eligible documents.

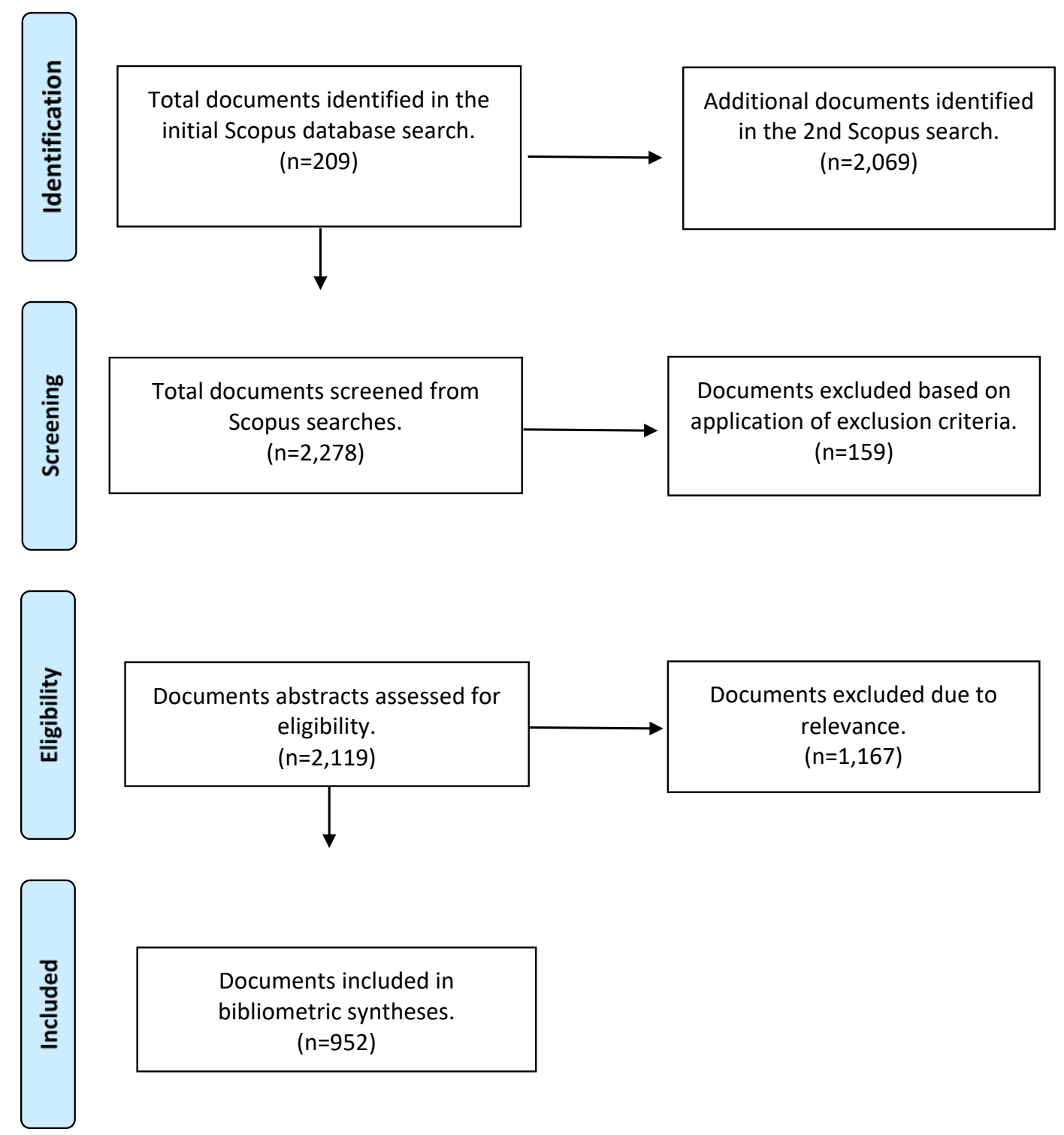

Figure 2. The Preferred Reporting Items for Systematic Reviews and Meta-Analyses (PRISMA) flow diagram detailing steps in the identification and screening of sources [73].

\subsection{Data Extraction}

In order to prepare the Scopus sources for the bibliometric analysis, we downloaded bibliographic data on the nine hundred and fifty-two articles, from Scopus in a .csv (comma-separated values) file. The stored data included the author name, author affiliation, article title, keywords, abstracts, and various citation data. This file was then uploaded into the VOSviewer bibliometric analysis software. A copy of the csv file, containing the same information, was also saved in Excel for supplementary descriptive data analyses. 


\subsection{Data Analysis}

Quantitative data analysis relied on descriptive statistics and bibliometric analysis. Descriptive analyses were conducted in order to document the basic features of the SL knowledge base, such as size, growth, and geographical distribution. Descriptive analyses were conducted both in Scopus as well Excel.

Bibliometric analysis employs both citation and 'co-citation' analysis to identify prominent authors, publications, and journals, within a domain of knowledge. Citation analysis calculates the number of times a document residing in the review database has been cited by another article in the index from which it came (e.g., Scopus). Related citation metrics (e.g., total citations, citations per document, and h-index) are interpreted as representing measures of scholarly influence.

Co-citation analysis offers different complementary insights into the scholarly influence $[36,40,74]$. As elaborated by Zupic and Čater [34], "co-citation is defined as the frequency with which two units (authors, journals, documents) are cited together" (p. 431). Co-citation analysis uses 'co-citation counts' to construct measures of similarity between documents, authors, or journals [69]. We have included Figure 3 to clarify the meaning, use, and implications of the co-citation analysis.

In Figure 3, the Mebratu [19] and Rodale [75] articles are considered 'co-cited documents' because they both appear in the reference lists of documents located in the review database. In Figure 3, each of the 'co-cited documents' $[19,75]$ would accrue three co-citations. From the perspective of science mapping, these articles are considered 'intellectually related' by virtue of their co-citation by other scholars $[34,69]$.

It should be further noted that in Figure 3, the Mebratu [19] article was not among the nine hundred and fifty-two documents included in the review database. Nonetheless, it was captured in the 'co-citation analysis' due to its inclusion in the 'reference lists' of documents that were in the database. This capability to include influential documents that may be located outside of the review database, and even outside of Scopus, enables co-citation analysis to provide complementary insights to those offered by traditional citation analysis.

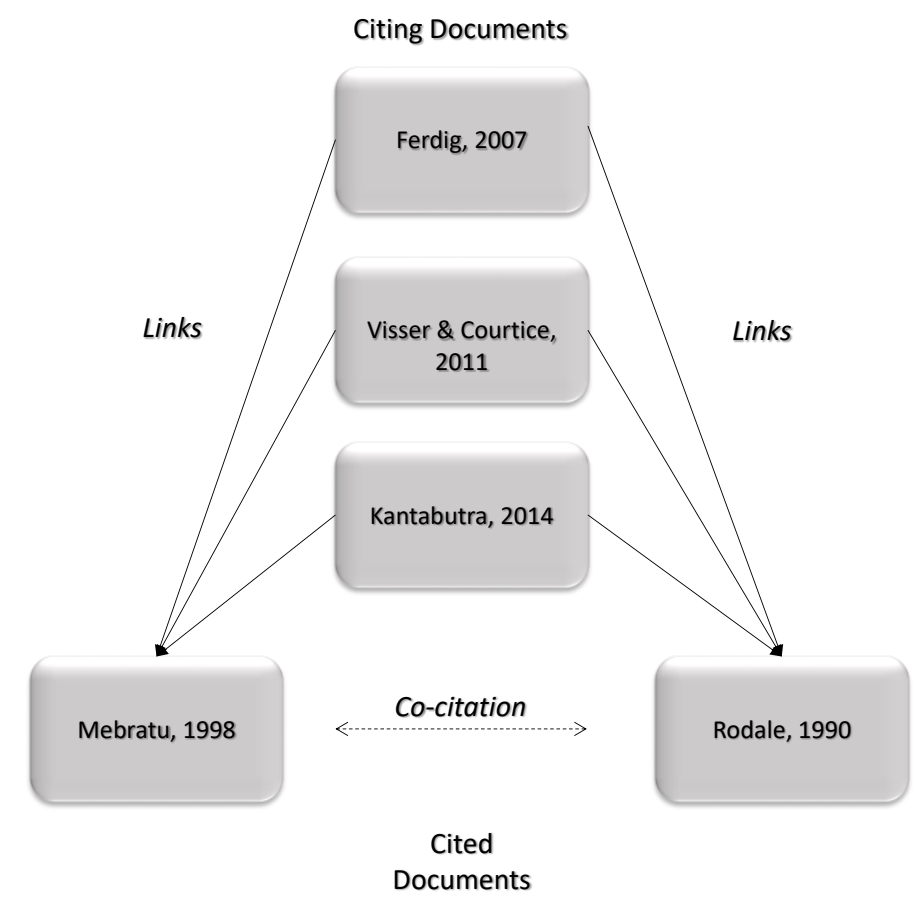

Figure 3. Example of document co-citation in science, mapping sustainable leadership.

Co-citation analysis comes in several variants: Journal Co-citation Analysis (JCA), Author Co-citation Analysis (ACA), and Document Co-citation Analysis (DCA). Each uses matrices of 
co-citation frequencies as the input for the analysis. These co-citation matrices serve as the basis for analytical techniques such as multi-dimensional scaling (MDS) and visualization of similarities (VOS) through bibliometric mapping [33,76]. In this review, VOSviewer software was used to create visual representations or 'network maps' of the relationships among multiple features of the sustainable leadership knowledge base.

\section{Results}

This section of the paper presents results with respect to patterns of SL knowledge production. Presentation of the results is organized around the foci embedded in the four research questions.

\subsection{Volume, Growth Trajectory, and Geographic Distribution of the SL Literature}

The total of nine hundred and fifty-two sustainable leadership documents accumulated since 1990 represents a modest body of knowledge. This knowledge base was comprised of six hundred and fifty-eight journal articles, one hundred and fifty-one conference proceedings, one hundred book chapters, and forty-three books. The literature on sustainable leadership began to slowly emerge, during the 1990s with the publication of thirty-three documents, one hundred and ninety-three documents during the 2000s, and seven hundred and twenty-six documents between 2010 and 2018. These data portray a modest literature of relatively recent vintage, but with a growth trajectory that reflects a heightened interest in sustainable leadership over the past decade (see Figure 4).

\section{Documents by year}

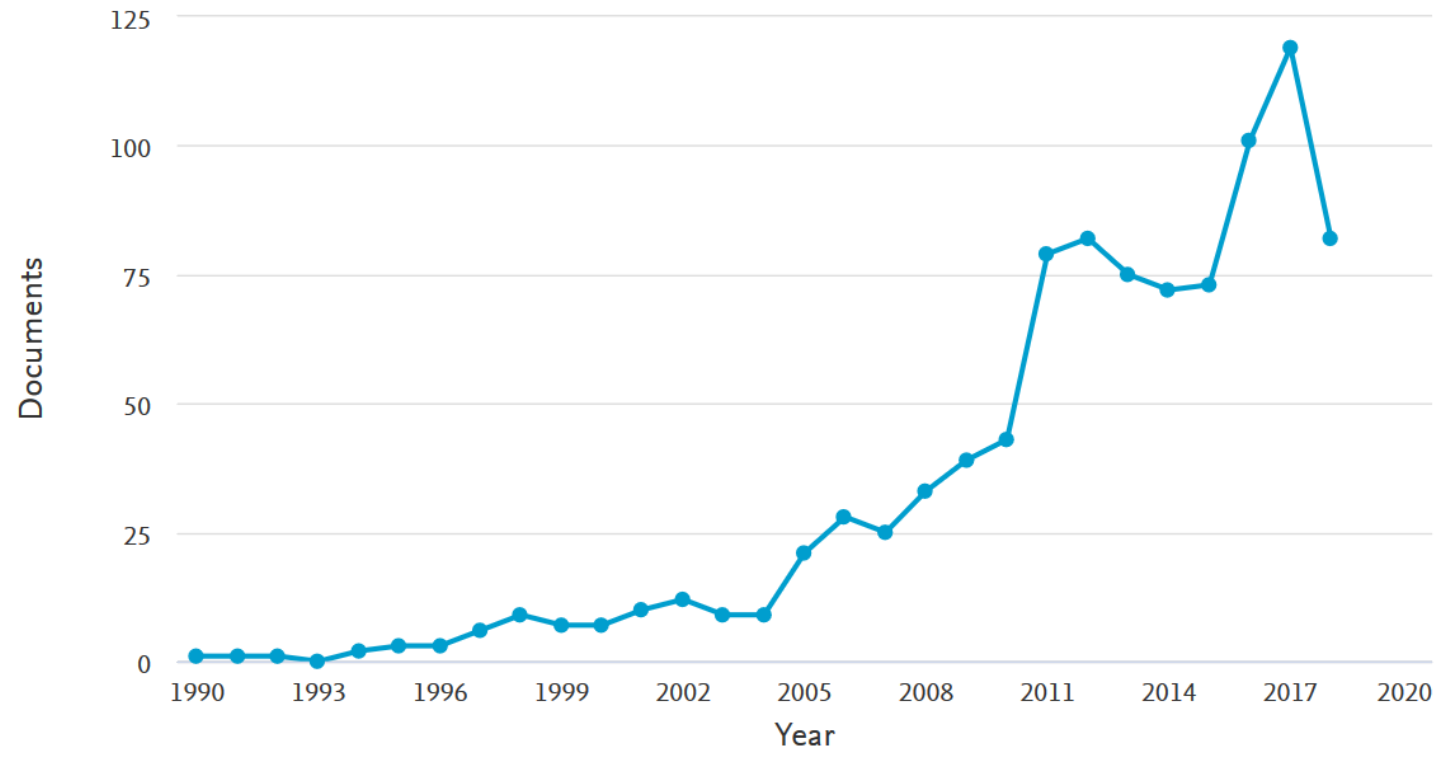

Figure 4. Growth trajectory of the sustainable leadership literature, 1990-2018 ( $\mathrm{n}=952)$.

The heat map in Figure 5 shows that SL knowledge production has been concentrated in the USA, Canada, UK, and Australia. These four societies account for five hundred and seventeen or $54 \%$ of our full corpus of SL documents. This finding is consistent with a broader trend in the management literature that finds a predominance of Anglo-American scholarship in management journals [77]. For example, the author's recent bibliometric analysis of The Leadership Quarterly found that Anglo-American scholarship accounted for over $75 \%$ of all articles published in the journal since its inception in 1990 [78]. Thus, the predominance of the Anglo-American scholarship should not be interpreted as evidence of greater interest in sustainability within these societies, but rather as a feature of scholarly publication in international management journals. 
Indeed, the SL knowledge base actually evidences surprising diversity. The SL literature contains ten or more contributions from societies located in Europe (e.g., Sweden, Germany, Spain, France, Netherlands, Belgium, Finland, Romania, Switzerland, Greece, and Italy), Asia (e.g., India, Thailand, Malaysia, Turkey, Indonesia, and Russia), Africa (South Africa), and Latin America (Brazil). Thus, while scholarship on sustainable leadership has been dominated by Anglo-American authors, the field is attracting interest among a global community of scholars.

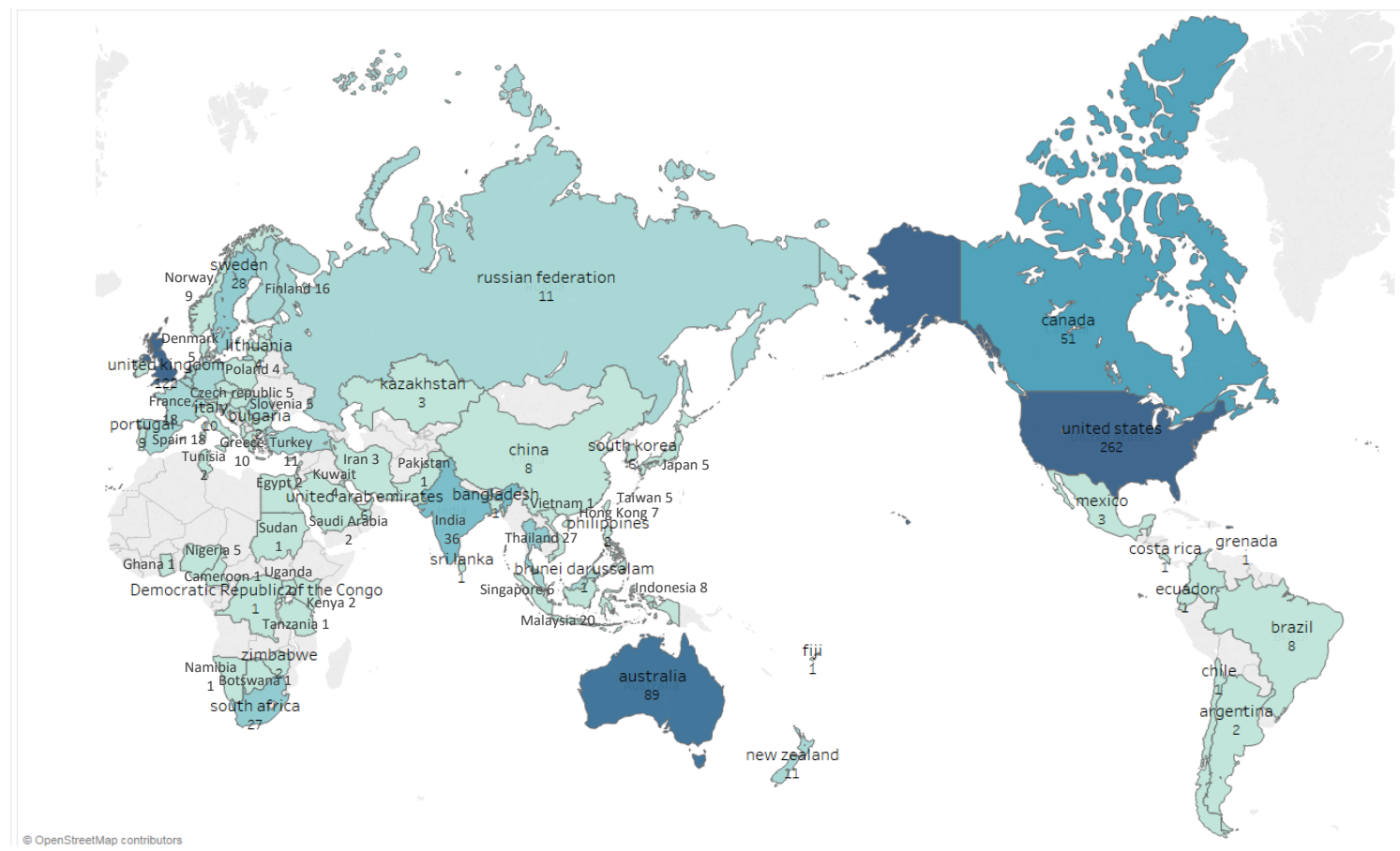

Figure 5. Global distribution of the sustainable leadership literature, 1990-2018 ( $\mathrm{n}=952)$.

\subsection{Analysis of Influential Journals, Authors, and Documents}

The next research question inquired into the composition of the knowledge base from the perspective of sources, scholars, and documents. The most highly-cited sources in this field of study consisted solely of journals (see Table 1). The twenty most highly-cited journals published one hundred and twenty articles, comprising $13 \%$ of the total document database. The distribution of documents across these twenty journals offers insight into the breadth, quality, and potential impact of scholarship in this domain.

The breadth of scholarship on sustainable leadership is indicated by a rather surprising mix of journal foci. The journals in Table 1 focus on business and management, management and strategy, education management, sustainability, and natural sciences. This suggests that scholarship on sustainable leadership is multi-disciplinary in nature and being applied across different types of organizations (e.g., private, public, education, healthcare, etc.).

Analysis of these journals by the Scopus Quartile offers a high inference assessment of the quality of SL scholarship, at least at the top end of the spectrum. More specifically, we found that nine of the 20 top-cited journals were ranked in $Q_{1}$, eight in $Q_{2}$, two in $Q_{3}$, and one in $Q_{4}$ of Scopus. This snapshot suggests that the most highly-cited scholarship on sustainable literature is being published in high quality journals, a reasonable proxy for research quality.

Another strength of the bibliometric analysis is the ability to identify key scholars and documents within a field of research $[35,36,69]$. Leading contributors to scholarship on sustainable leadership, as measured by the number of 'Scopus documents' (not tabled), include Kantabutra (14), Avery (9), Hargreaves (6), Suriyankietkaew (5), Benn (4), Maak (4), Pless (4), Bag (4), and Manz (4). As indicated 
in Table 2, the most influential scholars in the sustainable leadership literature, as measured by 'total Scopus citations', are Hargreaves, Benn, Avery, Kantabutra, Wilson, Metcalf, and Lenssen.

Table 1. Top twenty journals publishing scholarship on sustainable leadership ranked by Scopus citation impact.

\begin{tabular}{cllcccc}
\hline \multirow{2}{*}{ Rank } & \multicolumn{1}{c}{ Source } & Domain & $\begin{array}{c}\text { Number } \\
\text { of Docs }\end{array}$ & $\begin{array}{c}\text { Scopus } \\
\text { Cites }\end{array}$ & $\begin{array}{c}\text { Scopus } \\
\text { Quartile }\end{array}$ & $\begin{array}{c}\text { Total Link } \\
\text { Strength }\end{array}$ \\
\hline 1 & Journal of Bus Ethics & Bus \& Man & 17 & 351 & $\mathrm{Q} 1$ & 7 \\
2 & Int'1 Jnl of Sust in High Ed & Education & 11 & 130 & $\mathrm{Q} 1$ & 2 \\
3 & Learning Org & Education & 5 & 101 & $\mathrm{Q} 2$ & 3 \\
4 & Plos One & Science & 4 & 76 & $\mathrm{Q} 1$ & 0 \\
5 & Lship \& Org Dev Journal & Bus \& Man & 4 & 63 & $\mathrm{Q} 2$ & 0 \\
6 & Journal of Bus Strat & Strat \& Man & 4 & 59 & $\mathrm{Q} 3$ & 5 \\
7 & Journal of Ed Admin & Education & 4 & 58 & $\mathrm{Q} 1$ & 0 \\
8 & Journal of Cleaner Prod & Engineering & 4 & 50 & $\mathrm{Q} 1$ & 0 \\
9 & Journal of Man Dev & Bus \& Man & 6 & 48 & $\mathrm{Q} 2$ & 4 \\
10 & Journal of Forestry & Forestry & 4 & 45 & $\mathrm{Q} 1$ & 0 \\
11 & Ed Man Admin \& Lship & Education & 4 & 40 & $\mathrm{Q} 1$ & 0 \\
12 & Ind and Comm Training & Education & 14 & 38 & $\mathrm{Q} 2$ & 4 \\
13 & Total Qual Man \& Bus Excel & Bus \& Man & 6 & 36 & $\mathrm{Q} 1$ & 1 \\
14 & Journal of Org Change Man & Strat \& Man & 4 & 27 & $\mathrm{Q} 2$ & 1 \\
15 & Journal of Ed Change & Education & 4 & 26 & $\mathrm{Q} 1$ & 0 \\
16 & Int'1 Journal of Ed Man & Education & 5 & 23 & $\mathrm{Q} 2$ & 3 \\
17 & Forestry Chronicle & Forestry & 4 & 18 & $\mathrm{Q} 4$ & 0 \\
18 & Dev and Learning in Org & Education & 6 & 13 & $\mathrm{Q} 2$ & 0 \\
19 & Global Bus and Org Excel & Bus \& Man & 5 & 12 & $\mathrm{Q} 3$ & 6 \\
20 & Sustainability (Switz) & NA & 5 & 12 & $\mathrm{Q} 2$ & 4 \\
\hline
\end{tabular}

These data should, however, be interpreted with two cautionary caveats. First, even among these most highly-cited SL scholars, the actual level of Scopus citations is relatively low. Second, none of the scholars in Table 2 are readily identified among the top leadership scholars globally. These findings, therefore, further fill out our picture of sustainable leadership as an emergent knowledge base.

Table 2. Rank order of the twenty most highly cited authors on sustainable leadership, 1990-2018 (citations based on citations by other documents in the SCOPUS database).

\begin{tabular}{ccccccc}
\hline Rank & Author & Nation & Documents & Scopus Cities & CPD & Total Link Strength \\
\hline 1 & Hargreaves A. & USA & 6 & 325 & 54.2 & 13 \\
2 & Benn S. & Australia & 4 & 150 & 37.5 & 4 \\
3 & Avery G. & Australia & 7 & 135 & 16.3 & 76 \\
4 & Kantabutra S. & Thailand & 14 & 87 & 6.2 & 64 \\
5 & Wilson A. & UK & 2 & 87 & 6.2 & 64 \\
6 & Metcalf L. & Australia & 3 & 78 & 26.0 & 4 \\
7 & Lenssen G. & Belgium & 2 & 71 & 35.5 & 5 \\
8 & Maak T. & Swiss & 4 & 56 & 14.0 & 1 \\
9 & Pless N. & France & 4 & 56 & 14.0 & 1 \\
10 & Davies B. & UK & 3 & 53 & 17.7 & 0 \\
11 & Smith W. & USA & 2 & 52 & 26.0 & 0 \\
12 & Bergsteiner H. & Australia & 2 & 51 & 25.5 & 16 \\
13 & Campbell D. & Australia & 2 & 47 & 23.5 & 0 \\
14 & Parkin S. & UK & 2 & 42 & 21.0 & 0 \\
15 & Petrick J. & USA & 2 & 40 & 20.0 & 0 \\
16 & Quinn J. & USA & 2 & 40 & 20.0 & 0 \\
17 & Branco M. & Portugal & 2 & 38 & 19.0 & 0 \\
18 & Allen K. & USA & 2 & 37 & 18.5 & 0 \\
19 & Svensson G. & Norway & 3 & 36 & 12.0 & 0 \\
20 & Bag S. & India & 4 & 35 & 8.8 & 3 \\
\hline
\end{tabular}


Analysis of highly-cited documents in the SL knowledge base (see Table 3), largely reinforces the patterns reported above. For example, the most highly-cited documents listed in Table 3 are again dominated by Anglo-American scholars. While there is representation of scholars from other societies (e.g., Austria, Finland, Thailand, Hungary, Denmark, and Belgium), only three of these documents were authored in a developing society-Thailand [42,43,60]. Interest in sustainable leadership among Thai scholars can be linked to the commitment of the former King of Thailand, His Majesty the King Bhumipol Adulyadej, to an indigenous philosophy of sustainable development $[42,43,60,63,76]$. The relevance of this finding lies in the fact that sustainability issues are projected to have the most urgent and significant impact in developing societies around the world [20,44,68,72,77-86].

The list also offers insight into the organizational locus of these papers. Although the list was dominated by studies of sustainable leadership in business settings $[18,43,47,81]$, the highly-cited documents also include examinations of sustainable leadership in education organizations $[48,82,87,88]$. This variety supports the conclusion that this is a cross-sector literature.

The composition of a knowledge base can also be analyzed from the perspective of the types of documents. The most-highly-cited documents shown in Table 3 indicate a reasonable balance among conceptual, commentary, and empirical papers. However, only a single paper [29] was classified as a review of research. This is not unexpected given the recent vintage of this literature.

At the same time, the authors noted that the empirical studies tended to be case studies (not tabled) and none of the quantitative papers in the table employed large samples or advanced analytical methods. Due to the size of the full sample obtained for this review (i.e., nine hundred and fifty-two documents), the authors did not explore the range and adequacy of research methods being used by scholars contributing to this knowledge base. Nonetheless, we would surmise that if the top-cited papers did not examine the nature and impact of sustainable leadership across multiple organizations, this could reflect a trend in the broader SL literature.

Table 3. Rank order of the twenty most highly-cited sustainable leadership articles, 1990-2018 (citations based on citations by other documents in the SCOPUS database $(n=952)$.

\begin{tabular}{cllllcc}
\hline Rank & \multicolumn{1}{c}{ Document } & Society & Area & \multicolumn{1}{c}{ SL Focus } & Type of Paper & Scopus Cites \\
\hline 1 & Hargreaves \& Goodson [48] & USA/UK & Ed & Change & Emp & 178 \\
2 & Sahlberg [82] & Finland & Ed & Change & Com & 176 \\
3 & Thomas et al. [81] & USA & Bus & Ethics & Con & 105 \\
4 & Hargreaves \& Fink [88] & USA/Can & Ed & Integrated & Com & 95 \\
5 & Baumgartner [47] & Austria & Bus & Change & Emp & 88 \\
6 & Smith \& Sharicz [83] & Can/USA & Bus & Change & Emp & 72 \\
7 & Hind et al. [44] & UK/UK/Bel & Bus & Ld Dev & Emp & 66 \\
8 & Metcalf \& Benn [17] & Australia & Bus & Ethics & Con & 61 \\
9 & Avery [8] & Australia & Bus & Integrated & Con & 59 \\
10 & Gloet [84] & Australia & Bus & Ld Dev & Con & 54 \\
11 & Robinson et al. [31] & Canada & Bus & Integrated & Emp & 52 \\
12 & Hargreaves \& Fink [4] & USA/Can & Ed & Integrated & Con & 44 \\
13 & Avery \& Bergsteiner [25] & Australia & Bus & Integrated & Con & 43 \\
14 & Morsing \& Oswald [27] & Den/USA & Bus & Change & Emp & 37 \\
15 & Galpin \& Lee Whittington [29] & USA & Bus & Change & Rev & 26 \\
16 & Boiral et al. [18] & Canada & Bus & Env & Emp & 21 \\
17 & Paraschiv et al. [21] & Hungary & Bus & Env/Change & Com & 20 \\
18 & Kantabutra [42] & Thai & Bus & Integrated & Emp & 18 \\
19 & Kantabutra \& Siebenhüner [60] & Thai & Bus & Integrated & Emp & 16 \\
20 & Kantabutra \& Avery [57] & Thai/Aus & Bus & Integrated & Emp & 14 \\
\hline
\end{tabular}

In terms of conceptual foci, eight of the articles in Table 3 adopted holistic conceptualizations of sustainable leadership $[4,8,24,25,57,58,60,88]$. More specifically, these documents were organized, explicitly, around the concept of 'sustainable leadership' rather than a conceptual cousin, such as transformational, authentic or responsible leadership. The authors of these documents integrated social, economic, environmental, and change perspectives into their sustainable leadership models. 
Three of the top five documents, and seven overall, focused on sustainable leadership from the perspective of 'organizational change' $[21,27,29,47,82,83]$. These papers inquired into how leadership influences change processes and organizational culture in support of sustainability. This reflected a broader interest in change within this knowledge base [21,22,26,28,46,48]. Unlike authors who employed holistic models of sustainable leadership, however, these authors did not adopt a common perspective on the 'aims' or 'ends' of sustainability (e.g., social justice, environmental impact, cultural transmission).

We next supplemented these traditional citation analyses with 'document co-citation analysis' (DCA). As suggested earlier, DCA examines the extent to which documents in the review database have been 'co-cited' with documents located in the reference lists of the other SL documents. Notably, the co-cited papers in those reference list need not be in the review database, nor even in the Scopus index. This enables co-citation analysis to identify connections between documents in our review database and the broader literature. Thus, DCA arguably offers a broader assessment of scholarly influence than the traditional citation analysis, which is limited to the documents identified in our search of the Scopus index.

The DCA results in Table 4 reinforce several trends identified in the previous analyses. First, the level of co-citations shown in Table 4 are also relatively low. This reaffirms our assessment that this literature has yet to develop a coherent critical mass of high impact scholarship. Second, although the geographic distribution of documents is again concentrated in Anglo-American societies, there is also representation from Thailand, Norway, France, and Switzerland. Third, the journals in which these highly co-cited documents feature, are of generally high quality (e.g., Journal of Business Ethics, Academy of Management Review, Journal of Business Strategy).

Table 4. Rank order of the twenty most highly co-cited sustainable leadership documents, 1990-2018.

\begin{tabular}{cccc}
\hline Rank & Document & Society & Co-cites \\
\hline 1 & Piboolsravut [63] & Thai & 13 \\
2 & Albert [41] & Fra & 11 \\
3 & Porter and Kramer [89] & USA & 11 \\
4 & Hargreaves and Fink [88] & USA/Can & 11 \\
5 & Quinn and Dalton [90] & USA & 10 \\
6 & Kantabutra and Avery [57] & Thai/Aus & 9 \\
7 & Kantabutra [42] & Thai & 9 \\
8 & Eisenhardt [91] & USA & 9 \\
9 & Dunphy [92] & Aus & 8 \\
10 & Bergsteiner and Avery [93]. & Aus & 8 \\
11 & Kantabutra and Siebenhuner [60] & Thai & 8 \\
12 & Avery [8] & Aus & 8 \\
13 & Bass [14] & USA & 8 \\
14 & Schueth [94]. & USA & 7 \\
14 & Morsing and Oswald [27] & Norway & 7 \\
14 & Metcalf and Benn [17] & Aus & 7 \\
17 & Gelb and Strawer [95] & USA & 6 \\
18 & Watt [96] & Can & 6 \\
19 & Kantabutra [5] & Thai & 6 \\
20 & Dyllick and Hockerts [15] & Swiss/Fra & 6 \\
\hline
\end{tabular}

Finally, we noted that several documents featured on both the citation and co-citation lists $[17,27,43,57,60,88]$. As the co-citation counts are correlated with traditional citation counts, some overlap between documents in Tables 3 and 4 is expected. Nonetheless, overlap should not be taken as a given, leading us to conclude that these overlapping documents evidence the greatest influence within this literature. 


\subsection{Intellectual Structure of the Sustainable Leadership Knowledge Base}

Our third research question sought to illuminate the 'intellectual structure' underlying published theory and research in sustainable leadership. For this research question we conducted author co-citation analysis (ACA), an approach that has been widely used in science mapping of different disciplines [34-36,69]. We used VOSviewer for this analysis because it not only calculates author co-citations, but also generates a co-citation map that 'visualizes similarities' in the scholarship of authors [33].

The author co-citation map in Figure 6 shows nodes, each representing a different scholar. Size of the node reflects the number of author co-citations; larger nodes indicate scholars with more co-citations and a greater influence. Density of 'links' connecting scholars reflect the number of times a scholar has been co-cited by another scholar (see Figure 3). The map also groups authors into colored 'clusters' that serve as proxies for the 'Schools of Thought' that comprise the knowledge base $[33,69,74]$. Schools of Thought reflect common theoretical perspectives and lines of inquiry shared by groups of scholars [34,36,39].

Out of a total of thirty-five thousand six hundred and eighty-seven authors in the author co-citation network, one hundred and forty-five scholars met a threshold of at least twenty author co-citations. Figure 6 displays the eighty most highly co-cited authors in the co-citation network. The most highly 'co-cited authors' were Bass (158), Avery (152), Hargreaves (129), Avolio (128) and Kantabutra (101). Notably, the list of the top twenty co-cited authors on sustainable leadership, included six scholars who were not represented in the review database-Bass, Pfeffer, Porter, Senge, Argyris, and Mintzberg. Their inclusion in the co-citation map derives from the influence of their broader conceptual and empirical contributions to the literature in leadership and management which was cited by authors writing on sustainable leadership.

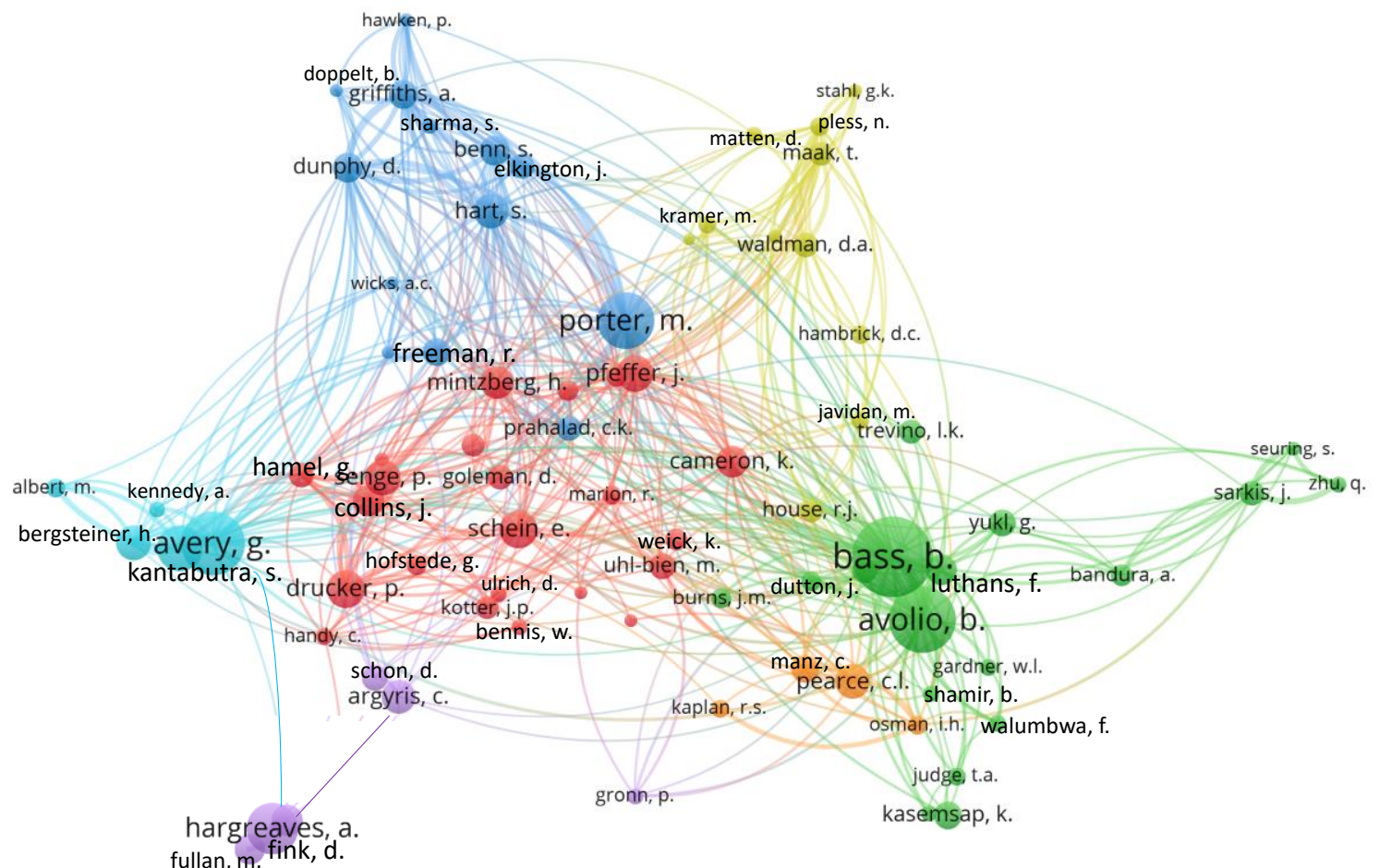

Figure 6. Author co-citation analysis of the sustainable leadership literature, 1990-2018 (threshold twenty citations, display eighty authors).

Author co-citation analysis was employed next to analyze the intellectual structure' of this knowledge base. In the author co-citation analysis, scholars are grouped into clusters on a network map based upon the 'similarity' of their co-cited works $[36,37,69]$. When interpreting the intellectual 
structure revealed in a co-citation map, one examines the nature of similarities in the scholarship of authors comprising each of the clusters [34,97]. Thus, interpretation of a co-citation map requires some degree of tacit knowledge of the literature. Alternatively, one can examine the published works of scholars on the map.

The co-citation map shows six 'Schools of Thought' in the literature on sustainable leadership. Scholars in five of the clusters or Schools have authored scholarship directly related to sustainable leadership (i.e., the yellow, purple, blue, light blue, and green clusters). The sixth School (i.e., the red cluster), centrally located in the map, is comprised of scholars associated with the Managerial Leadership. This includes scholars associated with organizational learning and change (e.g., Kotter, Drucker, Handy, Hamel, Collins, and Schein), as well as the management of complex organizations (e.g., Weick, Pfeffer, Mintzberg, Uhl-Bien, and Cameron). The centrality of this School on the map suggests that it has provided conceptual underpinnings for scholarship on sustainable leadership.

The Sustainability Schools highlighted on the map reflect different models and emphases within the literature on sustainable leadership. The light blue cluster led by Avery, Kantabutra and Bergsteiner, can be directly traced to the Rhineland model discussed earlier. It can be termed the Sustainable Leadership School. This school is associated with the values-based models of sustainable leadership that integrate social, economic, and environmental dimensions $[5,6,8,25]$. While this is a relatively small school, the size of the nodes of its key scholars reinforces its importance within this literature. Moreover, as suggested earlier, the authors located in this school, have made the greatest headway in defining and examining sustainable leadership as an independent construct.

The purple cluster, comprised of Hargreaves, Fink, Fullan, Argyris, and Schon represents the School of Leadership for Sustainable Change. While some scholarship from these authors has adopted a broader perspective on sustainable leadership [4], this School is grounded in research on sustainable change. Moreover, the three tightly linked scholars located at the bottom of this cluster (i.e., Hargreaves, Fink, Fullan) are primarily noted for their application of sustainability to education organizations $[48,87,88]$.

Located at the top of the map is the blue cluster, whose authors have focused on the Leadership for Corporate Sustainability. Scholars such as Griffiths, Benn, Freeman, and Dunphy have examined on how leaders engage stakeholders, create sustainable value, and enhance corporate social responsibility $[17,62,92,98]$. Other scholars in this School also are noted for research which studies how strategic leadership underlies corporate sustainability (e.g., Porter, Hawken, Prahalad, and Hart).

The yellow cluster consists of scholars associated with Responsible Leadership. Scholars such as Maak, Pless, Waldman, Matten, and Stahl have examined how leaders develop and model responsible business practices that foster corporate responsibility $[21,52,54,56]$. This school has also sought to understand how to develop responsible leaders whose visions incorporate sustainability commitments.

Scholars located in the green cluster, led by Bass and Avolio, are associated with Ethical and Transformational Leadership for Sustainability. For example, Avolio, Gardner, Walumbwa, Luthans, and Zhu are all associated with 'authentic leadership', a values-based leadership model that aims for a sustainable change. Bass, Avolio, Burns, Shamir, and Judge are noted for their research on transformational leadership, a model that is frequently linked to organizational change.

\subsection{Topical Foci of the Sustainable Leadership Knowledge Base}

For the final research question, we employed a keyword co-occurrence analysis, or co-word analysis, to identify topical trends in the sustainable leadership knowledge base. The rationale behind co-word analysis was articulated by Zupic and Čater [34]: "When words frequently co-occur in documents, it means that the concepts behind those words are closely related. The output of co-word analysis is a network of themes and their relations that represent the conceptual space of a field" (p. 435). Co-word analysis complements previous citation analyses by adding topical specificity to the sub-fields that comprise the SL scholarship [34,37].

The co-word search was set to All Keywords with a threshold of at least nine cases of a co-occurring keyword. The most commonly co-occurring keywords in the review database were 'sustainable 
development' (263 cases), 'leadership' (250 cases), 'organization and management' (89 cases), 'innovation' (64 cases), 'sustainable leadership' (44 cases), 'education' (42 cases), 'economics' (38 cases), 'organizations' (35 cases), 'societies and institutions' (35 cases), and 'information management' (34 cases). The prevalence of 'sustainable development' and 'leadership' suggests the intellectual homes from which sustainable leadership has emerged.

Co-word analysis has also been applied to identify the 'research front' in a knowledge base [34,97]. Price [40] defined 'research front' as the growing tip of the literature. The research front is dynamic, as scholars respond to changes in the research environment, as well as to the publication of new findings. Identification of the research front alerts scholars to the most recent topical trends in a literature.

In order to reveal the research front in the sustainable leadership literature, we used VOSviewer to generate a temporal overlay on a keyword co-occurrence map. This co-word map both visualizes similarities among frequently occurring keywords and classifies topics, according to their prevalence, across a specific period of time. Thus, the co-word map in Figure 7 shows the relative scholarly emphasis on different topics associated with sustainable leadership over the past decade.

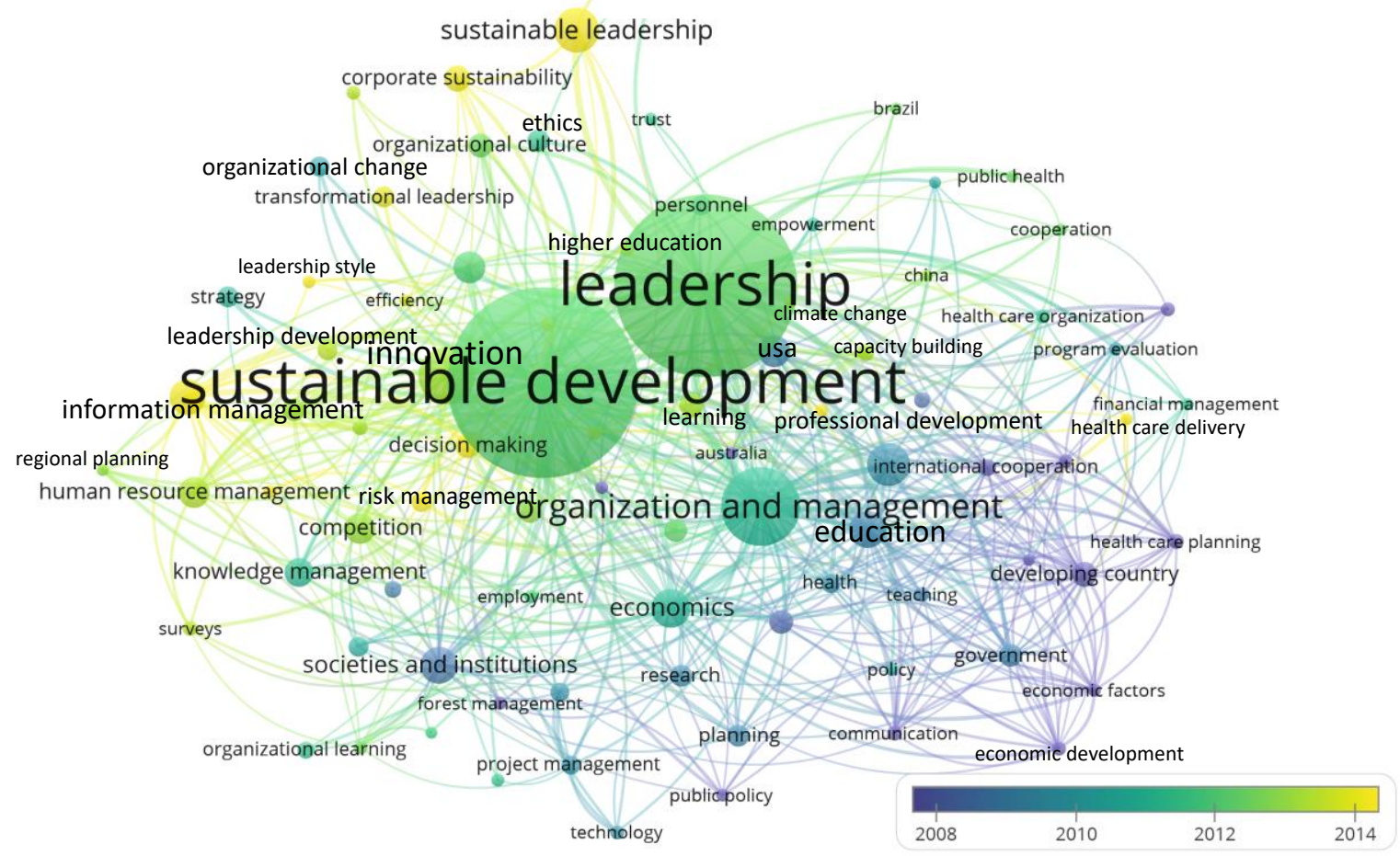

Figure 7. Temporal overlay on a keyword co-word occurrence map for sustainable leadership documents published from 1990-2018 (threshold nine co-occurrences, display eighty-five keywords).

Based on this co-word map, the research front in the sustainable leadership literature included the following topics ranked by recency and strength of interest-sustainable leadership, information management, corporate sustainability, transformational leadership, decision-making, risk management, higher education, culture, and professional development. These first-order topics were followed by a second-order cluster of change-related terms (i.e., innovation, capacity building, learning, training, human resource management, organizational culture, values). Taken together these suggest that the research front in sustainable leadership lies in understanding how leadership builds capacity for innovation and change needed to achieve the new goals associated with sustainable development. Indeed, related emphases on education, training, higher education, capacity building, and human resource management highlight the role leadership plays in enabling people to make the change to sustainable practices. 


\section{Discussion}

This research review employed science mapping as a means of enhancing our understanding of the knowledge base in sustainable leadership. Using bibliometric analysis, the authors analyzed nine hundred and fifty-two Scopus-indexed documents published between 1990 and 2018. This concluding section highlights limitations of the review and offers our interpretation of the findings.

\subsection{Limitations}

Science mapping provides a systematic, quantitative approach to analyzing the structure of a knowledge base. However, given its focus on 'meta-data' associated with documents comprising a body of knowledge, science mapping does not replace review methods that analyze substantive findings extracted from research papers. With this in mind, the current review only sets the stage for subsequent research syntheses that examine findings from studies of sustainable leadership.

A second limitation arises from our conceptual and operational definitions of 'sustainable leadership'. Given the recency of this literature, a consensus has yet to emerge on the 'conceptual boundaries' of this construct. Thus, as noted in this review, scholars have approached sustainable leadership from the perspective of responsible leadership [14,17,31,49,51], environmental leadership [15,18], and change leadership [21,22,28,46,88]. Still others have offered 'holistic' conceptualizations of sustainable leadership $[4,5,8,58]$. The limitation that arises from this feature of the literature lies in the ambiguity of the boundaries of the sustainable leadership construct, and therefore, the operational criteria used to select documents for review.

Given the fluidity of this literature's evolution, the authors dealt with this limitation at two levels. Conceptually, we adopted a broad perspective on sustainable leadership that did not give precedence to a specific model $[4,8]$. Second, during the search phase we relied on multiple sets of keywords (i.e., sustainable leadership and sustainability leadership) to identify documents for inclusion. This approach employed the assumption that if authors of the documents were adopting a 'sustainability perspective' on their exploration of a particular leadership model (e.g., transformational, change, or authentic leadership), this would be captured in the keywords included either in the title, author-assigned keywords, or the abstract.

Another limitation arises from our focus on Scopus-indexed documents. Although Scopus offers a more complete coverage of scholarly papers than the Web of Science, it does not encompass all extant documents within a given literature. Thus, the full sustainable leadership literature is, in fact, larger than we have characterized in this review. The impact of this limitation was reduced somewhat by the fact that co-citation analysis examines all documents included in the references lists of documents included in the review database. Thus, it captures a much broader set of documents than are encompassed within Scopus.

Finally, despite the quantitative rigor of bibliometric analysis, the interpretation of co-citation maps is not always straightforward. Arriving at the suitable threshold for co-citation analysis can also be challenging. Thus, Zupic and Čater [34] observed that 'making sense' of the output of co-citation analyses requires the scholar to already possess a relatively firm knowledge of the literature.

\subsection{Interpretation and Implications of the Findings}

This bibliometric review found that the knowledge base on sustainable leadership is modest in size, of recent vintage, and growing rapidly. While the first relevant documents appeared in the early 1990s, it was only during the past decade that a critical mass of SL scholarship began to emerge. Interest in exploring leadership that fosters sustainability in organizations and societies is increasingly global in scope. Citation analysis uncovered key documents that represent a ready reference list for interested scholars (e.g., see Tables 3 and 4). Author citation analyses found that key scholars in this domain come from a broad swathe of societies. These key scholars are located in Australia (e.g., Avery, Bergsteiner, Benn, Metcalf, and Gloet), USA (Hargreaves, Thomas, Avolio, Galpin, Petrick, 
Smith, Allen, and Quinn), UK (Hind, Wilson, Davies, and Parkin), Canada (Fink, Boiral, and Smith), Thailand (Kantabutra, Suriyankietkaew, Kasemsap, and Piboolsravut), France (Pless), Switzerland (Maak), Norway (Svensson), Portugal (Branc), India (Bag), Denmark (Morsing), Hungary (Paraschiv), and Austria (Baumgartner).

While the global scope of interest in sustainable leadership bodes well for future research, this review also identified a severe imbalance in the knowledge base on sustainable leadership. Indeed, with the exception of Thailand, we noted a paucity of relevant research on sustainable leadership from developing societies. Given the relevance of SDGs for developing societies [20,86], this limitation of the SL literature begs urgent redress. Thus, we call for research on how sustainable leadership emerges in developing societies around the world. Moreover, it is critical that this research surface the social-cultural forces that shape the enactment of sustainable leadership across different contexts and clarify the factors that contribute to positive effects on diverse outcomes.

Low inference assessments of the quality of this literature await reviews using alternate methods. However, inspection of the journals in which this literature appeared provided a positive first assessment of document quality. More specifically, seventeen of the twenty most highly-cited documents in the review database featured in Scopus Q1 and Q2 journals. In light of the fact that this is an emerging literature, this should be interpreted as a positive sign that at least a portion of the knowledge base meets a good quality standard.

Nonetheless, these positive trends are balanced by other data presented in this review. For example, even among the most highly-cited scholars writing on sustainable leadership, the level of citation impact is relatively low. Although this may be explained, in part, by the recent vintage of this literature, it suggests that sustainable leadership has yet to gain a firm foothold in the mainstream of either the leadership or sustainability literatures. We also observed that few of the highly-cited scholars in the SL knowledge base come from the ranks of widely known 'leadership scholars'. Finally, relatively few papers in the database were published in top-level leadership and management journals (e.g., Academy of Management journals, The Leadership Quarterly). These authorship patterns reinforce our conclusion that sustainable leadership remains an emerging line of inquiry within the parent domains of leadership and sustainable development.

Author co-citation analysis (ACA) revealed that the conceptual landscape of the sustainable leadership knowledge base is comprised of six Schools of Thought. One school, Managerial Leadership, consisted of authors whose scholarship provides the intellectual underpinnings for sustainable leadership. The other five schools were more directly concerned with how leadership contributes to sustainability in organizations and societies. These Schools included Sustainable Leadership, Leadership for Corporate Sustainability, Leadership for Sustainable Change, Responsible Leadership, and Ethical and Transformational Leadership.

The emergence of these Schools of Thought through co-citation analyses could not have been predicted prior to this review. If we reflect on the conceptual framework presented at the outset of the review (see Figure 1), only authors and documents associated with the Sustainable Leadership School addressed the full range of variables included in our conceptual model. While there were exceptions, authors in the other Schools tended to focus more narrowly on selected dimensions of sustainable leadership (e.g., ethical leadership, responsible leadership, environmental leadership, change leadership, corporate sustainability). Only scholars in the Sustainable Leadership School consistently tended to consistently addressed the full range of processes associated with leadership for sustainable development $[5,6,8,42,43,60,76]$.

Thus, for example, these authors have conceptualized and studied how values and context shape sustainable leadership $[8,41]$. They have also inquired into the nature of leadership practices that offer an inspiring vision of sustainability [59] and which engage stakeholders, create commitment, and move organizations towards long-term, sustainable development goals $[24,25,57,58,60]$. Notably, this body of work also conceptualizes the enactment of sustainable leadership within the broader social system, rather than as a closed system $[8,42,43,60,76]$. While systematic research synthesis of the 
five sustainable leadership schools is warranted, we suggest that the Sustainable Leadership School may offer the richest potential for moving this domain forward.

Synthesis of topics of recent interest, among SL scholars, yielded several topical clusters that comprise the current 'research front' in sustainable leadership. The first is 'sustainable leadership'. We interpret this to mean that scholars have begun to take an interest in 'sustainable leadership' as an independent construct, as opposed to applying other leadership models (e.g., transformational, ethical) to sustainable development in organizations and societies $[3,12,49]$. This further reinforces our conclusion concerning the potential of the Sustainable Leadership School.

The second topical cluster in the research front is 'innovation and change'. This cluster incorporates related but distinct foci. The first, somewhat older, studies focused on how leadership contributes to sustainable change $[26,45,46,48,82,87]$. The more recent literature within this topical cluster examines how leaders help their organizations innovate and make the change to sustainability $[21,22,24,28,47]$. This topical cluster affirms the importance of placing the innovation capacity at the center of the sustainability processes.

The third cluster of keywords is linked to both of the above topical clusters. It focuses on capacity-building at both the organizational (e.g., training and professional development) and societal levels (e.g., education, higher education, and students). This highlights the role that capacity building plays in making the change to sustainability $[17,18,28,58]$. Capacity building means changing attitudes and behaviors of staff in organizations, as well as developing a generation of leaders with the mindset and skills to achieve sustainable development goals $[24,26,44,54,84]$.

While the method of this review did not delve into the findings of particular studies, the authors can offer some limited insights concerning the implications for practice. First, the review reinforces the importance of values and ethics as a foundation for sustainable leadership. These precursors to leadership practice pervaded all of the Schools of Thought identified in the author co-citation analysis. Whether one seeks to adopt an authentic, responsible, transformational, or sustainable approach to leadership, the clarification, articulation, and enactment of personal and shared values is a critical first step towards motivating and engaging others. Moreover, sustainable leadership does not assume that 'all values are equal'. Thus, this literature emphasizes values such as gender and social equality, environmental stewardship, moderation, prudence, compassion, empowerment, and innovation.

A second practical implication is the need to adopt a long-term perspective towards the multiple ends towards which one leads an organization or society. It is the responsibility of leaders to 'sell' the value of long-term goals such as environmental stewardship and survival of the organization or society over quick fixes. The importance of this perspective and capability is highlighted in the difficulties faced by the current political leaders throughout the world. However, the difficulty in gaining broad commitment towards long-term goals does not diminish its importance.

Third, one of the underemphasized concepts discussed in this literature is the 'sustainability mindset' $[8,57,58]$. A sustainability mindset evolves as a leader embraces a particular set of values (see above), enacts them in practice, and gains positive results. Leaders who develop a sustainability mindset over time will 'naturally' model the espoused vision of sustainability. This, in turn, strengthens engagement, motivation, and commitment among stakeholders.

Fourth, sustainable leadership is oriented towards capacity building and sustainable change. Consistent with the emphasis on long-term results, vision articulation is paired with ongoing capacity development. This is designed to achieve the new goals' that sustainable development frequently entails. Thus, sustainable leadership incorporates change leadership.

This review also holds implications for theory-building and future research. As elaborated above, this review finds the greatest potential for theory building in the Sustainability School. While this School of Thought shares features with the other Schools, it is the only one that offers a comprehensive model of how and why sustainable leadership can achieve its aims. Indeed, the School is the only one that incorporated all features of the model proposed in Figure 1. 
At the same time, research conducted, to date, on Sustainable Leadership, consists primarily of case studies and single company quantitative surveys $[5,24,25,57-60,76]$. While these results are generally positive, they do not constitute rigorous tests of the adequacy of the conceptual model. Multi-organization, comparative studies will offer more insight into the efficacy of sustainable leadership when analyzed in terms of its broader goals. Similarly, studies of other leadership models that have been applied to 'sustainability' should also be studied in terms of broader goals, and not simply traditional measures of staff job satisfaction, commitment, and job performance.

\section{Conclusion}

This science mapping review of the research on sustainable leadership was the first, large-scale, systematic review undertaken on this topic. Previous scholars examining this domain of sustainability research adopted more narrowly-focused lenses and employed qualitative review methods [4,23,29]. It is hoped that our findings will offer encouragement and a direction to future scholarship that examines sustainable leadership in organizations and society.

Author Contributions: P.H. conceptualized the study, gathered the document database, and participated in data analysis and preparation of the manuscript. S.S. participated in data analysis and preparation of the manuscript.

Acknowledgments: This research was funded by a grant from the Thailand Sustainable Development Foundation, Bangkok, Thailand.

Conflicts of Interest: There were no conflicts of interest among the authors.

\section{References}

1. Yukl, G. Effective leadership behavior: What we know and what questions need more attention. Acad. Manag. Perspect. 2012, 26, 66-85. [CrossRef]

2. Bass, B.M. Two decades of research and development in transformational leadership. Eur. J. Work Organ. Psychol. 1999, 8, 9-32. [CrossRef]

3. Kim, W.G.; Brymer, R.A. The effects of ethical leadership on manager job satisfaction, commitment, behavioral outcomes, and firm performance. Int. J. Hosp. Manag. 2011, 30, 1020-1026. [CrossRef]

4. Hargreaves, A.; Fink, D. Sustainable Leadership; John Wiley \& Sons: New York, NY, USA, 2007.

5. Kantabutra, S. Putting Rhineland principles into practice in Thailand: Sustainable leadership at a bathroom design company. Glob. Bus. Organ. Excell. 2012, 31, 6-19. [CrossRef]

6. Kantabutra, S. Measuring corporate sustainability: A Thai approach. Meas. Bus. Excell. 2014, 18, 73-88. [CrossRef]

7. Maak, T.; Pless, N.M. Responsible leadership in a stakeholder society: A relational perspective. J. Bus. Ethics 2006, 66, 99-115. [CrossRef]

8. Avery, G. Leadership for Sustainable Futures: Achieving Success in a Competitive World; Edward Elgar Publishing: Cheltenham, UK, 2005.

9. Scott, W.R. Organizations and Organizing: Rational, Natural and Open Systems Perspectives; Routledge: New York, NY, USA, 2015.

10. Thompson, J.D. Organizations in Action: Social Science Bases of Administrative Theory; Routledge: New York, NY, USA, 2017.

11. Colbert, B.A.; Kurucz, E.C. Three conceptions of triple bottom line business sustainability and the role for HRM. People Strateg. 2007, 30, 21-29.

12. Fry, L.W.; Slocum, J.W., Jr. Maximizing the triple bottom line through spiritual leadership. Organ. Dyn. 2008, 37, 86-96. [CrossRef]

13. Hubbard, G. Measuring organizational performance: Beyond the triple bottom line. Bus. Strateg. Environ. 2009, 18, 177-191. [CrossRef]

14. Bass, B. Leadership and Performance Beyond Expectations; Free Press: New York, NY, USA, 1985.

15. Dyllick, T.; Hockerts, K. Beyond the business case for corporate sustainability. Bus. Strateg. Environ. 2002, 11, 130-141. [CrossRef]

16. Marshall, J.; Coleman, G.; Reason, P. Leadership for Sustainability: An Action Research Approach; Routledge: London, UK, 2017. 
17. Metcalf, L.; Benn, S. Leadership for sustainability: An evolution of leadership ability. J. Bus. Ethics 2013, 112, 369-384. [CrossRef]

18. Boiral, O.; Baron, C.; Gunnlaugson, O. Environmental leadership and consciousness development: A case study among Canadian SMEs. J. Bus. Ethics 2014, 123, 363-383. [CrossRef]

19. Mebratu, D. Sustainability and sustainable development: Historical and conceptual review. Environ. Impact Assess. Rev. 1998, 18, 493-520. [CrossRef]

20. Sachs, J.D. From millennium development goals to sustainable development goals. Lancet 2012, 379, 2206-2211. [CrossRef]

21. Paraschiv, D.M.; Nemoianu, E.L.; Langă, C.A.; Szabó, T. Eco-innovation, responsible leadership and organizational change for corporate sustainability. Amfiteatru Econ. J. 2012, 14, 404-419.

22. Sotarauta, M.; Horlings, I.; Liddle, J. (Eds.) Leadership and Change in Sustainable Regional Development; Routledge: London, UK, 2012.

23. Visser, W.; Courtice, P. Sustainability Leadership: Linking Theory and Practice. Unpublished work. 2011.

24. Avery, G.C.; Bergsteiner, H. How BMW successfully practices sustainable leadership principles. Strateg. Leadersh. 2011, 39, 11-18. [CrossRef]

25. Avery, G.C.; Bergsteiner, H. Sustainable leadership practices for enhancing business resilience and performance. Strateg. Leadersh. 2011, 39, 5-15. [CrossRef]

26. Day, C.; Schmidt, M. Sustaining resilience. In Developing Sustainable Leadership; Davies, B., Ed.; Paul Chapman: London, UK, 2007; pp. 65-86.

27. Morsing, M.; Oswald, D. Sustainable leadership: Management control systems and organizational culture in Novo Nordisk A/S. Corp. Gov. 2009, 9, 83-99. [CrossRef]

28. Ferdig, M.A. Sustainability leadership: Co-creating a sustainable future. J. Chang. Manag. 2007, 7, 25-35. [CrossRef]

29. Galpin, T.; Lee Whittington, J. Sustainability leadership: From strategy to results. J. Bus. Strateg. 2012, 33, 40-48. [CrossRef]

30. Lourenço, I.C.; Callen, J.L.; Branco, M.C.; Curto, J.D. The value relevance of reputation for sustainability leadership. J. Bus. Ethics 2014, 119, 17-28. [CrossRef]

31. Robinson, M.; Kleffner, A.; Bertels, S. Signaling sustainability leadership: Empirical evidence of the value of DJSI membership. J. Bus. Ethics 2011, 101, 493-505. [CrossRef]

32. Shriberg, M.; MacDonald, L. Sustainability leadership programs: Emerging goals, methods \& best practices. J. Sustain. Educ. 2013, 5, 44-58.

33. Van Eck, N.J.; Waltman, L. Citation-based clustering of publications using CitNetExplorer and VOSviewer. Scientometrics 2017, 111, 1053-1070. [CrossRef]

34. Zupic, I.; Čater, T. Bibliometric methods in management and organization. Organ. Res. Methods 2015, 18, 429-472. [CrossRef]

35. Nerur, S.P.; Rasheed, A.A.; Natarajan, V. The intellectual structure of the strategic management field: An author co-citation analysis. Strateg. Manag. J. 2008, 29, 319-336. [CrossRef]

36. White, H.D.; McCain, K.W. Visualizing a discipline: An author co-citation analysis of information science, 1972-1995. J. Am. Soc. Inf. Sci. 1998, 49, 327-355.

37. Boyack, K.; Börner, K.; Klavans, R. Mapping the structure and evolution of chemistry research. Scientometrics 2008, 79, 45-60. [CrossRef]

38. Giaretta, P.; Guarino, N. Ontologies and knowledge bases towards a terminological clarification. In Towards Very Large Knowledge Bases: Knowledge Building \& Knowledge Sharing; IOS Press: Amsterdam, The Netherlands, 1995; Volume 25, pp. 307-317.

39. Pilkington, A.; Meredith, J. The evolution of the intellectual structure of operations management-1980-2006: A citation/co-citation analysis. J. Oper. Manag. 2009, 27, 185-202. [CrossRef]

40. Price, D.J.D.S. Networks of scientific papers. Science 1965, 149, 510-515. [CrossRef]

41. Albert, M. The Rhine model of capitalism: An investigation. Eur. Bus. J. 1992, 4, 8-22.

42. Kantabutra, S.; Suriyankietkaew, S. Sustainable leadership in a Thai healthcare services provider. Int. J. Health Care Qual. Assur. 2011, 24, 67-80. [CrossRef]

43. Kantabutra, S. Examining relationships between organic leadership and corporate sustainability: A proposed model. J. of App. Bus. Res. 2013, 28, 67-80. [CrossRef]

44. Hind, P.; Wilson, A.; Lenssen, G. Developing leaders for sustainable business. Corp. Gov. 2009, 9, 7-20. [CrossRef] 
45. Kotter, J.P. Leading change. Harv. Bus. Rev. 2007, 85, 96-103.

46. Schneider, B.; Brief, A.P.; Guzzo, R.A. Creating a climate and culture for sustainable organizational change. Organ. Dyn. 1996, 24, 7-19. [CrossRef]

47. Baumgartner, R.J. Organizational culture and leadership: Preconditions for the development of a sustainable corporation. Sustain. Dev. 2009, 17, 102-113. [CrossRef]

48. Hargreaves, A.; Goodson, I. Educational change over time? The sustainability and nonsustainability of three decades of secondary school change and continuity. Educ. Adm. Q. 2006, 42, 3-41. [CrossRef]

49. Brown, M.E.; Treviño, L.K. Ethical leadership: A review and future directions. Leadersh. Q. 2006, 17, 595-616. [CrossRef]

50. Vlachos, P.A.; Panagopoulos, N.G.; Rapp, A.A. Feeling good by doing good: Employee CSR-induced attributions, job satisfaction, and the role of charismatic leadership. J. Bus. Ethics 2013, 118, 577-588. [CrossRef]

51. Avolio, B.J.; Gardner, W.L. Authentic leadership development: Getting to the root of positive forms of leadership. Leadersh. Q. 2005, 16, 315-338. [CrossRef]

52. Orlitzky, M.; Siegel, D.S.; Waldman, D.A. Strategic corporate social responsibility and environmental sustainability. Bus. Soc. 2011, 50, 6-27. [CrossRef]

53. Székely, F.; Knirsch, M. Responsible leadership and corporate social responsibility: Metrics for sustainable performance. Eur. Manag. J. 2005, 23, 628-647. [CrossRef]

54. Pless, N.M.; Maak, T.; Stahl, G.K. Developing responsible global leaders through international service-learning programs: The Ulysses experience. Acad. Manag. Learn. Educ. 2011, 10, 237-260.

55. Hay, R. The relevance of ecocentrism, personal development and transformational leadership to sustainability and identity. Sustain. Dev. 2010, 18, 163-171. [CrossRef]

56. Waldman, D.A.; Siegel, D.S.; Javidan, M. Components of CEO transformational leadership and corporate social responsibility. J. Manag. Stud. 2006, 43, 1703-1725. [CrossRef]

57. Kantabutra, S.; Avery, G.C. Sustainable leadership at Siam Cement Group. J. Bus. Strateg. 2011, 32, 32-41. [CrossRef]

58. Kantabutra, S.; Avery, G. Sustainable leadership: Honeybee practices at a leading Asian industrial conglomerate. Asia-Pac. J. Bus. Adm. 2013, 5, 36-56. [CrossRef]

59. Kantabutra, S.; Avery, G.C. Vision effects in customer and staff satisfaction: An empirical investigation. Leadersh. Organ. Dev. J. 2007, 28, 209-229. [CrossRef]

60. Kantabutra, S.; Siebenhüner, T. Predicting corporate sustainability: A Thai approach. J. Appl. Bus. Res. 2011, 27, 123-133. [CrossRef]

61. Avery, G.C.; Bergsteiner, H. Sustainable Leadership: Honeybee and Locust Approaches; Routledge: London, UK, 2012.

62. Petrick, J.A.; Scherer, R.F.; Brodzinski, J.D.; Quinn, J.F.; Ainina, M.F. Global leadership skills and reputational capital: Intangible resources for sustainable competitive advantage. Acad. Manag. Perspect. 1999, 13, 58-69. [CrossRef]

63. Piboolsravut, P. Sufficiency economy. ASEAN Econ. Bull. 2004, 21, 127-134. [CrossRef]

64. Youssef, C.M.; Luthans, F. Positive organizational behavior in the workplace: The impact of hope, optimism, and resilience. J. Manag. 2007, 33, 774-800. [CrossRef]

65. Lipsey, M.W.; Wilson, D.B. Practical Meta-Analysis; Sage Publications: Thousand Oaks, CA, USA, 2001.

66. Kuhn, T.S. The Structure of Scientific Revolutions; University of Chicago Press: Chicago, IL, USA, 2012.

67. House, R.J.; Hanges, P.J.; Javidan, M.; Dorfman, P.W.; Gupta, V. (Eds.) Culture, Leadership, and Organizations: The GLOBE Study of 62 Societies; Sage Publications: Thousand Oaks, CA, USA, 2004.

68. Hallinger, P. Bringing context out of the shadows of leadership. Educ. Manag. Adm. Leadersh. 2018, 46, 5-24. [CrossRef]

69. McCain, K.W. Mapping authors in intellectual space: A technical overview. J. Am. Soc. Inf. Sci. 1990, 41, 433-443. [CrossRef]

70. Fahimnia, B.; Sarkis, J.; Davarzani, H. Green supply chain management: A review and bibliometric analysis. Int. J. Prod. Econ. 2015, 162, 101-114. [CrossRef]

71. Mongeon, P.; Paul-Hus, A. The journal coverage of Web of Science and Scopus: A comparative analysis. Scientometrics 2016, 106, 213-228. [CrossRef]

72. Falagas, M.E.; Pitsouni, E.I.; Malietzis, G.A.; Pappas, G. Comparison of PubMed, Scopus, web of science, and Google scholar: Strengths and weaknesses. FASEB J. 2008, 22, 338-342. [CrossRef] 
73. Moher, D.; Liberati, A.; Tetzlaff, J.; Altman, D.G. Preferred reporting items for systematic reviews and meta-analyses: The PRISMA statement. Ann. Internal Med. 2009, 151, 264-269. [CrossRef]

74. Small, H. Visualizing science by citation mapping. J. Am. Soc. Inf. Sci. 1999, 50, 799-813. [CrossRef]

75. Rodale, R. Sustainability: An opportunity for leadership. In Sustainable Agricultural Systems; Edwards, C., Lal, R., Madden, P., Miller, R., House, G., Eds.; St. Lucie Press: Boca Raton, FL, USA, 1990; pp. 77-86.

76. Suriyankietkaew, S.; Avery, G.C. Employee satisfaction and sustainable leadership practices in Thai SMEs. J. Glob. Responsib. 2014, 5, 160-173. [CrossRef]

77. Hallinger, P. Science mapping the knowledge base on educational leadership and management from the emerging regions of Asia, Africa and Latin America. Educ. Manag. Adm. Leadersh. in press.

78. Hallinger, P. Science Mapping Leadership Research: A Bibliometric Analysis of The Leadership Quarterly, 1990-2018; The Center for Research on Sustainable Leadership, Mahidol University: Bangkok, Thailand, Unpublished work.

79. Gladwin, T.N.; Kennelly, J.J.; Krause, T.S. Shifting paradigms for sustainable development: Implications for management theory and research. Acad. Manag. Rev. 1995, 20, 874-907. [CrossRef]

80. Stern, D.I.; Common, M.S.; Barbier, E.B. Economic growth and environmental degradation: The environmental Kuznets curve and sustainable development. World Dev. 1996, 24, 1151-1160. [CrossRef]

81. Thomas, T.; Schermerhorn, J.R., Jr.; Dienhart, J.W. Strategic leadership of ethical behavior in business. Acad. Manag. Perspect. 2004, 18, 56-66. [CrossRef]

82. Sahlberg, P. Education policies for raising student learning: The Finnish approach. J. Educ. Policy 2007, 22, 147-171. [CrossRef]

83. Smith, P.A.; Sharicz, C. The shift needed for sustainability. Learn. Organ. 2011, 18, 73-86. [CrossRef]

84. Gloet, M. Knowledge management and the links to HRM: Developing leadership and management capabilities to support sustainability. Manag. Res. News 2006, 29, 402-413. [CrossRef]

85. Kantabutra, S.; Suriyankietkaew, S. Sustainable leadership: Rhineland practices at a Thai small enterprise. Int. J. Entrep. Small Bus. 2013, 19, 77-94. [CrossRef]

86. Griggs, D.; Stafford-Smith, M.; Gaffney, O.; Rockström, J.; Öhman, M.C.; Shyamsundar, P.; Steffen, W.; Glaser, G.; Kanie, N.; Noble, I. Policy: Sustainable development goals for people and planet. Nature 2013, 495, 305-307. [CrossRef] [PubMed]

87. Fullan, M. Leadership E Sustainability: System Thinkers in Action; Corwin Press: Thousand Oaks, CA, USA, 2005.

88. Hargreaves, A.; Fink, D. The seven principles of sustainable leadership. Educ. Leadersh. 2004, 61, 8-13.

89. Porter, M.E.; Kramer, M.R. Strategy and society: The link between competitive advantage and corporate social responsibility. Harvard Bus. Rev. 2006, 84, 78-92.

90. Quinn, 1.; Dalton, M. Leading for sustainability: Implementing the tasks of leadership. Corp. Gov. 2009, 9, 21-38. [CrossRef]

91. Eisenhardt, K. Building theories from case study research. Acad. Manage. Rev. 1989, 14, 532-550. [CrossRef]

92. Dunphy, D. Sustainability: Seize the strategic opportunity. Exec. Excell. 2004, 21, 19-24.

93. Bergsteiner, H.; Avery, G. How to kill a sustainable enterprise: A not so fictional case. Inter. J. Environ. Cultural Econ. Soc. Sustain. 2006, 2, 95-106. [CrossRef]

94. Schueth, S. Socially responsible investing in the United States. J. Bus. Ethics 2003, 43, 189-194. [CrossRef]

95. Gelb, D.; Strawer, J. Corporate social responsibility and financial disclosures. J. Bus. Ethics 2001, 33, 1-13. [CrossRef]

96. Watt, D. Is SRI sustainable? Benefits Can. 2003, 27, 62-65.

97. Boyack, K.W.; Klavans, R. Co-citation analysis, bibliographic coupling, and direct citation: Which citation approach represents the research front most accurately? J. Am. Soc. Inf. Sci. Technol. 2010, 61, 2389-2404. [CrossRef]

98. Griffiths, A.; Petrick, J.A. Corporate architectures for sustainability. Int. J. Oper. Prod. Manag. 2001, 21, 1573-1585. [CrossRef]

(C) 2018 by the authors. Licensee MDPI, Basel, Switzerland. This article is an open access article distributed under the terms and conditions of the Creative Commons Attribution (CC BY) license (http:/ / creativecommons.org/licenses/by/4.0/). 